\title{
Individualism, Structuralism, and Climate Change
}

\author{
Michael Brownstein ${ }^{a}$, Daniel Kelly ${ }^{b}$ and Alex Madva ${ }^{c}$ \\ ${ }^{a}$ Department of Philosophy, John Jay College and The Graduate Center, New York, NY, USA; ${ }^{b}$ Department of \\ Philosophy, Purdue University, West Lafayette, USA; 'Department of Philosophy, Cal Poly Pomona, Pomona, USA
}

\begin{abstract}
Scholars, journalists, and activists working on climate change often distinguish between "individual" and "structural" approaches to decarbonization. The former concern choices individuals can make to reduce their "personal carbon footprint" (e.g. eating less meat). The latter concern changes to institutions, laws, and other social structures. These two approaches are often framed as oppositional, representing a mutually exclusive forced choice between alternative routes to decarbonization. After presenting representative samples of this oppositional framing of individual and structural approaches in environmental communication, we identify four problems with oppositional thinking and propose five ways to conceive of individual and structural reform as symbiotic and interdependent.
\end{abstract}

\section{ARTICLE HISTORY}

Received 16 February 2021

Accepted 13 September 2021

\section{KEYWORDS}

Structural change; individual action; mitigation; decarbonization

\section{Introduction}

Scholars, journalists, and activists working on climate change often distinguish between "individual" and "structural" approaches to decarbonization. The former concern behaviors and consumption choices individual citizens can make to reduce their "personal carbon footprint" (e.g. eating less meat). The latter focus instead on institutions that shape collective action, especially state and national laws, industrial policies, and international treaties. While the distinction between individualism and structuralism - the latter of which we understand broadly to include approaches described as "institutional," "systemic," and "collectivist" - is intuitive and ubiquitous, the two approaches are often portrayed as oppositional, as if one or the other is the superior route to decarbonization, and as if pursuing one is somehow antithetical to pursuing the other.

One form this opposition takes in public discourse is whether individual action "matters," or rather whether it is negligible because what's "really" important is structural change. Representative headlines that allude to this opposition include "You Can't Save the Climate by Going Vegan" (Mann \& Brockopp, 2019) and "I Work in the Environmental Movement. I Don't Care if You Recycle" (Heglar, 2019). Similarly, a popular online meme in 2021 depicted the massive Ever Given ship stuck in the Suez Canal (Yee \& Glanz, 2021) with a comparatively tiny excavator attempting to dig it out, in apparent futility. In one tweet (with over 7,400 likes; Mauldin, 2021), the Ever Given is explicitly compared to a "structural problem" while the excavator is compared to "making different personal choices." In another (with over 2,100 likes; Thaler, 2021), the Ever Given is compared to "climate change" and the excavator to "individual actions." 

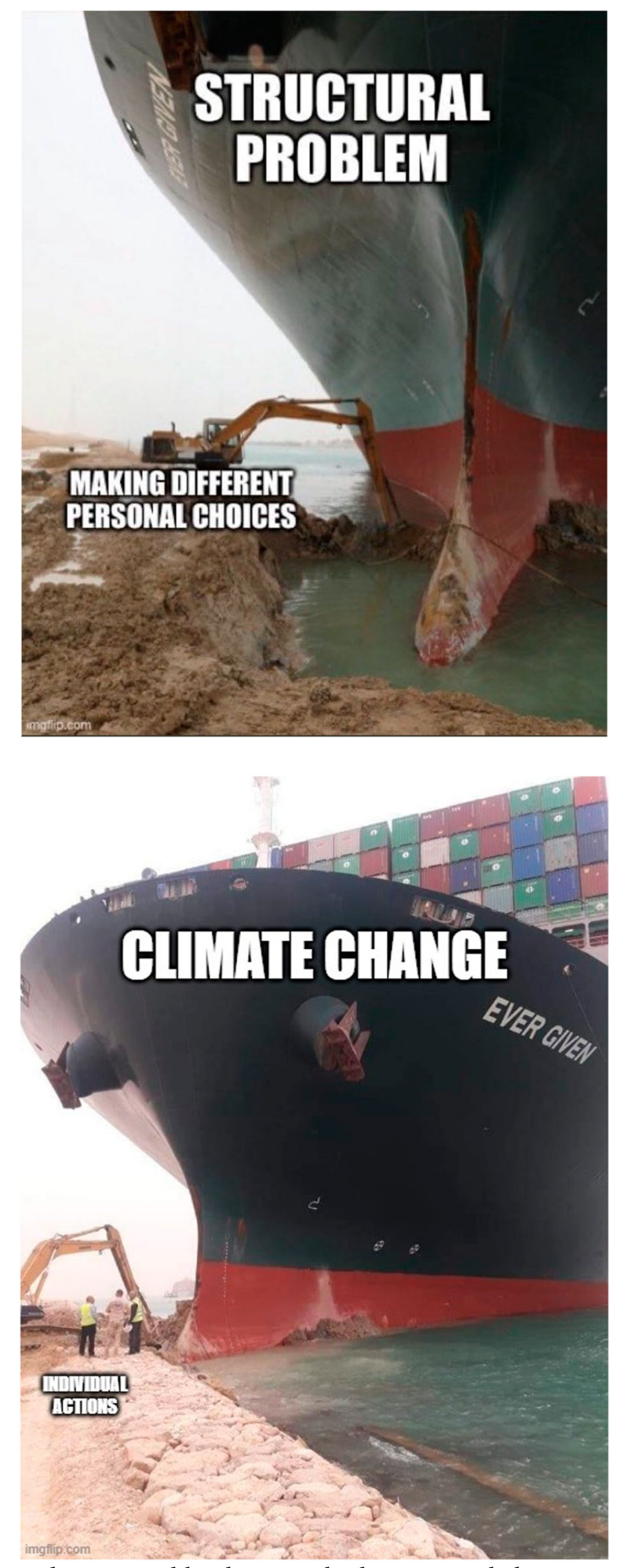

Familiar headlines and contrasts like these imply that personal choices are irrelevant to addressing the climate crisis, and that the only thing that will move the needle are changes to corporate practices, government policies, and other social systems. In his "Weekly Planet" newsletter 
published by The Atlantic, journalist Robinson Meyer explicitly endorses the irrelevance of personal behavior relative to system-wide change. Having described the massive decline of greenhouse gas emissions in 2020 (due to the pandemic), he concludes, "But that behavioral change was not enough to meet even the least ambitious of America's long-term climate goals. This extraordinary and painful trial should provide the final proof, I think, that climate change simply cannot be solved by changing our personal behavior. We have to change systems, and the only way to do that is to develop and deploy technologies that will enable economic prosperity without carbon pollution" (1.12.21). The oppositional view Meyer expresses has captured widespread interest. On February 4th, 2021, for example, a piece entitled "How Useful is Recycling, Really?" was the second most popular article on The Atlantic's homepage.

In this paper, we offer further representative samples of either/or oppositional thinking as it arises in scholarly research on climate change. We then identify four problems with the general oppositional framing of structural and individual reform. We propose five ways to think "symbiotically" instead. Our proposals are based on a synthesis of evidence that draws on research in environmental communication (e.g. Mitra, 2016; Nisbet, 2009; Norton, 2007; Scheufele et al., 2004; Whitmarsh et al., 2011) as well as a number of other social scientific disciplines (e.g. Brownstein, 2018; Davidson \& Kelly, 2020; Madva, 2016, 2017, 2020; Nielsen et al., 2020; Schmitt et al., 2020). A symbiotic conception of structural and individual reform rejects the either/or thinking of the oppositional frame and ultimately promotes a "both/and" approach to meeting the climate crisis. Instead of debating whether to focus either on personal lifestyle and consumer change or corporate and policy change, advocates should instead think in terms of "both/and" packages of changes. These will identify which specific individual-level changes in lifestyle, consumption, and activism best complement those specific structural transformations to economies and political systems that will combat climate change, and vice versa. In sum, for every structural reform to prioritize, there are certain individual reforms to prioritize because they contribute to achieving that structural reform. And for each individual reform to prioritize, there are particular structural reforms to put in place because they incentivize, nudge, convince, or enable individuals to make the prescribed behavioral changes. Individuals and structures are interdependent and mutually supporting. Our argument aims to show that continued attention to the features of both - as well as the interactions between them - is necessary for meaningful action on climate change. We conclude with directions for further research to better understand the effects of oppositional vs. symbiotic frames, with an eye toward identifying communication strategies better suited to meet the climate crisis.

\section{Individualism and structuralism in Climate Politics and activism}

The current debate over action on climate change is a specific instance of a more general dialectic that has a long and rich history. Indeed, "the" dispute between individualists and structuralists is not actually a single disagreement but a family of thematically related debates. These include social scientific debates about the relative influence of individual agency versus structural factors in driving historical change (Sewell, 2005), political debates pitting libertarians and liberal individualists against socialists and communitarians (Bell, 2020; Bird, 1999), and methodological debates about suitable explanations of social behavior (Dumont, 1986; Elster, 1989; Giddens, 1986; Haslanger, 2015). Concepts and assumptions from many of these literatures inform two long-standing streams of research and activism on environmental protection, sustainability, and decarbonization. For a schematic attempt to capture the leading "sides" and "arguments" as they appear in American public discussion of climate change, see Table 1 .

While we believe that symbiotic thinking about how individuals shape and are shaped by systems and cultures can be usefully applied across different cultures (e.g. Markus \& Kitayama, 2010), this essay is focused on English-speaking, particularly American, climate change discourse. Individualism has been particularly salient in American history and culture, and has taken many forms - perhaps mostly recognizably in "the myth of rugged individualism" (Grandin 2019, 130; also see Emerson 1841) - and animated many other related trends, including consumerism, egoism, self- 
Table 1.

\begin{tabular}{|c|c|c|}
\hline Topic & Structuralist Claim & Individualist Claim \\
\hline $\begin{array}{l}\text { Causal } \\
\text { Insignificance }\end{array}$ & $\begin{array}{l}\text { Individual consumer choices } \\
\text { cannot make a material } \\
\text { difference to atmospheric GHG } \\
\text { concentrations. Only changes to } \\
\text { "hard" structures such as laws } \\
\text { and material infrastructures can } \\
\text { have the requisite causal } \\
\text { impacts. }\end{array}$ & $\begin{array}{l}\text { It is precisely the "hardness" of } \\
\text { entrenched structures that } \\
\text { makes efforts to change them } \\
\text { causally insignificant. In the } \\
\text { face of immovable structures, } \\
\text { it's rational for individuals to do } \\
\text { what they can, e.g. by changing } \\
\text { consumption habits. }\end{array}$ \\
\hline
\end{tabular}

Breadth, Depth, Rather than focus on idiosyncratic Durability

Victim Blaming

Distraction

Meta-
Structuralist
Belief

Corporate and State Responsibility issues (e.g. meat consumption), "deeper" and lasting change is needed which addresses the "root" or "underlying" causes of the climate crisis (e.g. economies reliant on fossil fuel extraction and political ideologies such as "neoliberalism").

Ordinary people-especially the global poor-suffer the worst effects of climate change. Asking them to make sacrifices to reduce their carbon footprint unjustly puts the onus on the victims to solve a problem that they did not create.

Preoccupation with individual (consumer) choice distracts from more effective activities like climate activism (Frank, 2020). "Greenwashing" has been effective for diverting attention from corporate malfeasance to consumer-based "green" identity signaling (Oreskes \& Conway, 2010).

Belief systems are consequences of structural phenomena. People subscribe to individualist worldviews because they live in societies organized around individual liberty, and the pursuit of personal wealth and happiness. Inequality increase people's beliefs in individual responsibility for one's fate (García-Sánchez et al., 2019). Changing widely-held beliefs requires changing structures.

100 companies are responsible for producing $70 \%$ of global GHGs since 1988 (Griffin, 2017). The worst offenders have known for decades that their product would
Change occurs when individuals are persuaded to make different choices (cf., declines in smoking and drunk driving in the United States).

All paths to decarbonization must include rapid and massive "demand-side" increases in consumer desire for low-carbon products (e.g. electric cars and electrification of home heating).

"Green" consumer behavior is not sufficient to solve the climate crisis, but purchasing lowcarbon products is virtuous and beneficial.

Culture is the product of individuals' choices and values. Structural phenomena like inequality are the product of widely-held meritocratic beliefs.

Corporations and governments are run by individuals, who must be persuaded to enact climate friendly structural changes.
Interdependence

Structural reforms causally depend on individual changes, and vice versa. Therefore, if consumption choices like plant-based diets and recycling are insignificant, there are other changes individuals must make to transform climate structures. The causal impacts of individual choices and structural reforms must be assessed empirically, including consideration of investments of effort against expected outcomes. See §4.3.

Deep and durable change is needed, but because of the potential for "failed success" of structural reform-i.e. changes that create backlash sufficient to undo them (e.g. Prohibition in the United States) - structural change must ensure popular support.

Holding individuals responsible for helping to solve collective problems need not entail blaming them (Anderson, 2010; Zheng 2018). Individuals have responsibilities to others given their distinctive social roles (e.g. citizens must vote, businessowners must decarbonize their production chains).

The crucial empirical question is in when "green" consumer behavior complements or substitutes for structurallyoriented behavior. Identity and consistency effects may drive "green consumers" to be more rather than less likely to engage in climate activism (\$3.2).

Widely held beliefs both cause and are caused by structural phenomena. For example, $\mathrm{CO} 2$ removal technologies like carbon capture and storage are likely necessary for reaching global net-zero emissions. Public support for $\mathrm{CO} 2$ removal technologies is weak in part because they are seen as "too slow" and as failings to address "root causes." (Cox et al., 2020)

Corporate and government behavior is constrained by "hard" structures, such as law and public policy, as well as "soft" structures, such as social norms, 
Table 1. Continued.

\begin{tabular}{|c|c|c|c|}
\hline Topic & Structuralist Claim & Individualist Claim & Interdependence \\
\hline & $\begin{array}{l}\text { create the climate crisis; their } \\
\text { response was to fund } \\
\text { misinformation campaigns about } \\
\text { climate science (Oreskes \& } \\
\text { Conway, 2010). They must be } \\
\text { held accountable by legislative } \\
\text { enaction of pro-climate laws and } \\
\text { policy. }\end{array}$ & & $\begin{array}{l}\text { e.g. mandating a narrow } \\
\text { commitment to lobbyists and } \\
\text { stakeholders' financial interests } \\
\text { (§4.2). Changing corporate and } \\
\text { state behavior requires changing } \\
\text { these hard and soft structures of } \\
\text { incentives and constraints, which } \\
\text { requires, in turn, action by other } \\
\text { institutionally-empowered } \\
\text { individuals (e.g. media elites, } \\
\text { "social referents," community } \\
\text { leaders, norm entrepreneurs, } \\
\text { and the ordinary people who } \\
\text { must organize to hold } \\
\text { empowered individuals } \\
\text { accountable ( } \$ 4.2,4.4 ; \text { Raymond } \\
\text { et al., 2014; Raymond 2016)). }\end{array}$ \\
\hline
\end{tabular}

improvement, and settler colonialism (Elliott, 2004; Henrich, 2020; Nisbett, 2004; Rand, 1964; Taylor, 1989). The criticisms we describe below are often offered as correctives against this deep cultural tradition. Future research might investigate whether alternative cultural ideologies, such as certain indigenous or ecofeminist traditions (Singer, 2020; Vinyeta et al., 2015), are better poised to articulate symbiotic conceptions of the relations between selves, cultures, and structures.

The form of individualism we focus on is recognizable as a founding ethos of the modern environmental movement, captured by an anti-pollution Earth Day poster from 1970:

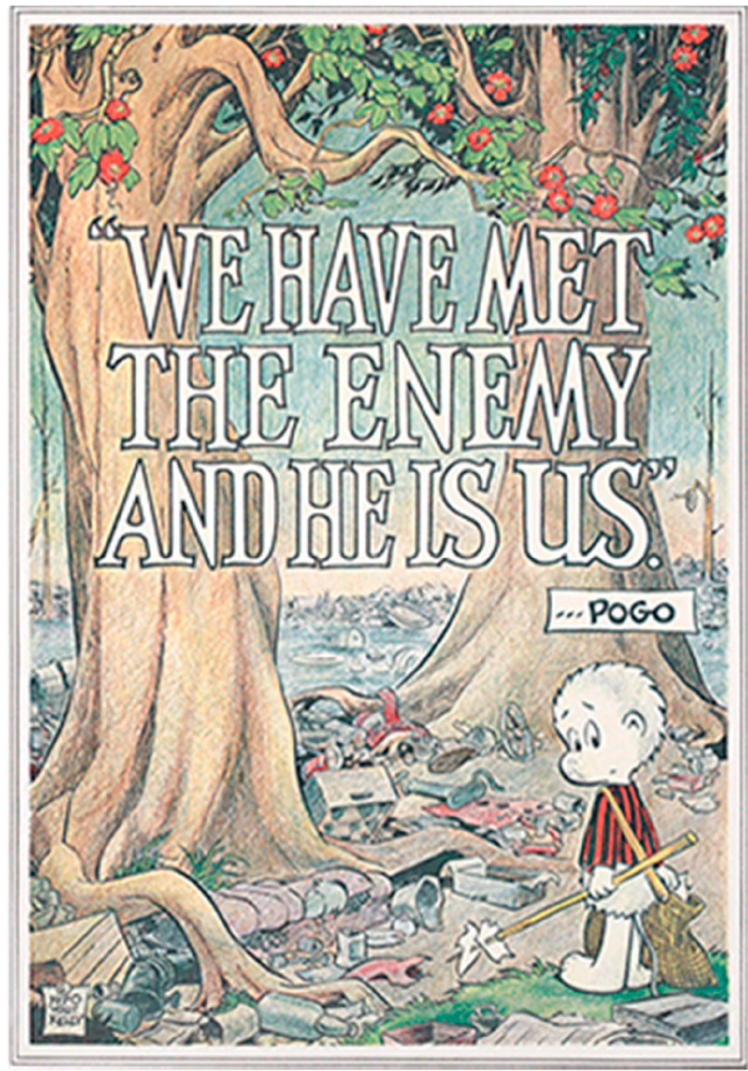


It suggests that environmental degradation results from the accumulation of many individuals' wasteful and careless actions. It also implies a solution: individuals can be better stewards of the earth, not just by reducing and properly disposing of their waste, but by taking more active personal steps, such as recycling, picking up litter, and buying more environmentally friendly products. The expanse of garbage in the poster implies that the task might be daunting, but we can solve it by each individually taking responsibility for our own local corner of the world.

Several lines of research commonly framed as individualist investigate ways to promote personal stewardship of this kind. One aims to identify drivers of pro-climate action by isolating key variables of individuals, such as beliefs about climate change (Leiserowitz et al., 2020), political attitudes (Bolsen \& Druckman, 2018), personality traits (Soutter et al., 2020), and moral frameworks (Feinberg \& Willer, 2013). A complementary literature measures the aggregative effects of the personal choices explained by such variables. For example, Wynes and Nicholas (2017) ranked 148 lifestyle choices to determine which most effectively reduce one's personal "carbon footprint." The four most impactful things individuals can do according to their analysis (which relies on a notion of "impactful" that we interrogate in \$4.2) are have one fewer child, live car-free, fly less, and adopt a plant-based diet. Research of this kind informs trade nonfiction - books such as The Climate Diet: 50 Ways to Trim Your Carbon Footprint (Greenberg, 2021) - as well as corporate messaging, as seen in blog posts such as "9 Things You Can Do to Save the Environment," which refers to consumption habits like eating, water usage, and "fixing" rather than "buying" things (Sunday, 2017). A large body of environmental communication research has explored which frames are most effective for encouraging individuals to change personal consumption habits like these (e.g. Cheng et al., 2011; Gifford \& Comeau, 2011; Lorenzoni et al., 2007; McDonald, 2009; Shih \& Lin, 2017).

In addition, a set of philosophical questions - also commonly construed as individualist - focus on whether people are morally obliged to adopt such practices (Broome, forthcoming; Hourdequin, 2010; Sinnott-Armstrong, 2005). Other philosophers have examined environmental morality through the lens of individual virtues and vices: Jamieson (2007) argues that people should cultivate virtues like humility, mindfulness, and temperance in the era of anthropogenic climate change, while Hourdequin (2010) raises moral issues related to hypocrisy by considering whether it is possible for a person who drives an inefficient car for pleasure to be genuinely concerned about climate change.

Research commonly construed as "structuralist" abstracts away from individuals, or holds these individual-difference variables constant, and instead focuses on identifying drivers of climaterelated outcomes exogenous to individuals. These include government type (Harrison \& Sundstrom, 2007), industrial arrangements (Mildenberger, 2020), policy design and costs (Bechtel \& Scheve, 2013), regional wealth (Franzen \& Vogl, 2013), cues from political elites (Gustafson et al., 2019), media tropes (e.g. tropes about national identity; Olausson, 2010; Post et al., 2019), and "the structural power of business interests" to dominate media coverage and public debate about the climate (Wetts, 2020; see also Wetts, 2019). Scholars of environmental communication have highlighted phenomena such as personalization, a common style of reporting that presents climate news as a dramatized "game among elites, such as who is winning or losing the debate" (Nisbet 2009, 18). According to Boykoff and Boykoff (2007):

Instead of concentrating on power, context, and process, the media tend to personalize social issues, focusing on the individual claims-makers who are locked in political battle. In other words, the macro is foregone in favor of the micro; structural or institutional analyses are skipped over in favor of personalized stories that stress the trials and tribulations of individuals. Only seldom are these personalized stories linked to deeper social analysis... The personalization of the climate-change narrative deflects attention from the roots of the problem, favoring the strategic moves of individuals over the political contexts in which they operate. $(1192,1197)$

Objections to the journalistic norms that prescribe reporting of this type fit into the either/or frame: they criticize the overly individualistic focus as coming at the expense of directing attention to more important supra-personal structural factors. 
Similarly, structuralist interventions designed to create change are broadly aimed at manipulating institutions, understood as the "rules of the road" that shape individuals' decisions and behaviors (North, 1991). For example, Trumbo and Shanahan (2000, p. 200) write, "The conditions that brought us climate change, as well as the conditions surrounding future options for dealing with it, are embedded in socioeconomic structures and value systems, embracing material advancement and fossil fuels - structures and values that are highly resistant to change." The familiar idea that climate change is an enormous collective action problem whose solution will require binding international treaties (e.g. Gardiner, 2011) is similarly structuralist in spirit, as are calls for limiting population growth or ending global capitalism. Proponents often imply that only proposals like these, which address the social structures within which individual agency is exercised, suffice to address the relevant challenges. Relatedly, environmental communication scholars have studied individuals' perceptions of the structural obstacles that make it difficult for them to minimize their personal carbon footprint, such as the absence of efficient public transportation (e.g. Jarreau et al., 2017; Lorenzoni et al., 2007; Whitmarsh et al., 2011). Some invocations of structuralism even include explicit dismissals of the individualist ethos, by, for example, pointing out that concepts like "litterbug" and "personal carbon footprint" were created by industrial polluters to deflect attention and responsibility from themselves. These can be found both in academic research (Elliot, 2016; Parr, 2012; Stuart et al., 2020; Webb, 2012) as well as in popular essays whose titles highlight their antagonism (as discussed above).

\section{Oppositional thinking}

In this section, we identify four potential causes of oppositional thinking about the relationship between individual and structural action. We hypothesize that these causes represent some of the psychological roots that make the either/or frame compelling.

As intuitively compelling as it may be, our concern is that framing individual and structural action as in competition with each other - as mutually-exclusive alternatives rather than mutually-supporting complements-stymies progress in meeting the climate crisis. The prevalence of the oppositional framework risks perpetuating false debate, thwarting theoretical collaboration, diffusing activists' energy, and blocking the development of a richer, more synthetic strategic imagination for guiding social change.

A few clarifications and caveats before moving on: we make no ontological claims, and so are neither denying the existence of either individuals or social structures nor denying the usefulness of the distinction between them in some contexts. Rather than "picking sides," we support an integrative approach, and in $\$ 4$ develop several ways that crucial structural and individual changes are both required to address the climate crisis.

\subsection{The duck-Rabbit problem of social behavior}

A helpful metaphor for thinking about the interrelation between individuals and structures is the famous duck-rabbit illusion.

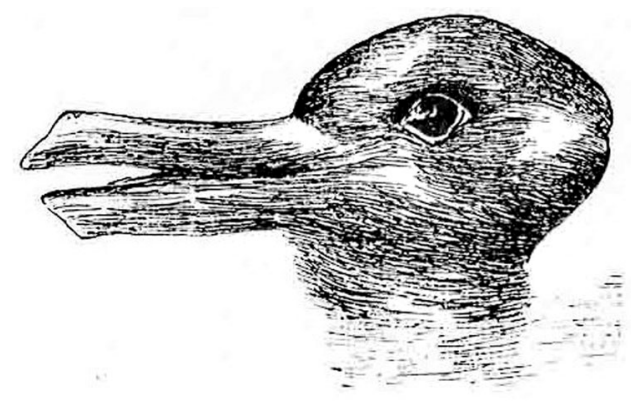


People see either a duck or a rabbit but not both at the same time; bringing one to attention inevitably forces the other into the background. But those features of the picture relegated to background remain, and remain essential to its composition. While we can only see the duck or the rabbit at a single time, the image itself is a product of the relations between all its elements, regardless of which ones we attend to.

Likewise, while different members of the climate community rightly focus on how different elements of society affect the climate, we maintain that it is as fruitless to debate the primacy of individuals or structures as it is to debate whether the image is really a duck or a rabbit. The most effective strategies for change will target both. However, just as it is difficult or impossible to see the figure simultaneously as both a rabbit and a duck, we hypothesize that the oppositional framing of individuals and structures retains intuitive appeal.

Thus note that in many cases, a single initiative designed to create social change can be plausibly framed as individualist or as structuralist, depending on which features of the initiative are emphasized in communication about it. Consider a few concrete cases:

E-Scooters: Italy is awarding $500 €$ grants to city-dwellers who purchase bicycles or e-scooters. These awards can be framed as an individualist reform because they aim to encourage individual citizens to reduce their carbon footprint by reducing their personal use of automobiles. These awards can also be framed as a structuralist reform because they are made possible by a far-reaching nationwide public policy that aims to change the incentives that structure individuals' choices.

Phone banking: You volunteer with an organization to make phone calls to persuade voters in your town to vote for political representatives who support a "Green New Deal." This action can be framed as individualist because you are trying to persuade other people to change their behavior one-by-one. This action can also be framed as structuralist because it is part of a collective action movement seeking to change political behavior (e.g. voting for a policy to fundamentally restructure the American economy).

Solar Panels: Choices made by homeowners to install solar panels shape and are shaped by their neighbors' choices (Bollinger \& Gillingham, 2012). Peer pressure is demonstrably powerful (Frank, 2020). A county program publicizing local solar installations to increase uptake of residential rooftop solar can be framed as individualist because it targets people as consumers. It can also be framed as structuralist because it motivates action by changing people's perceptions of what is common and expected in their social world.

COVID-19: The economic slowdown caused by the coronavirus pandemic created a temporary reduction in global emission of approximately $6.4 \%$ in 2020 as compared to 2019 (Tollefson, 2021). This was the largest single year drop off in modern history. This temporary reduction in global emissions can be framed as vindicating individualism because it demonstrates the enormous changes people can make if they choose to alter their behavior. It can also be framed as a vindication of structuralism because these individual changes resulted from a profound "shock to the system" that was enforced by emergency, top-down, state-based policy changes.

Like the duck-rabbit, these examples show how the very same phenomenon can be plausibly interpreted as vindicating either individualism or structuralism. It can be difficult to "see" both at the same time, just as one can see only the duck or the rabbit at once. We hypothesize that some sources for this difficulty include the prevailing conceptual tools for understanding and communicating about climate change.

\subsection{Overgeneralizing from specific outcomes}

Familiar criticisms of individualist approaches to climate change include the ideas that individual consumer choices cannot make a material difference to atmospheric GHG concentrations; that asking ordinary people to make sacrifices to reduce their carbon footprint unjustly puts the onus on victims to solve a problem that they did not create; and that preoccupations with individual action, culpability, and purity distract from more effective structural interventions (Boykoff \& Boykoff, 2007; Hagmann et al., 2019; Heglar, 2019; Mann \& Brockopp, 2019; Merritt et al., 2010).

We grant that some individual choices are ineffective for addressing the climate crisis, but maintain that the lesson to draw from this is that those specific choices are the wrong ones to make. It is a 
mistake to leap to generalizations about all individual choices, or to conclude that any changes to individual behavior are thereby also ineffective. (For discussion, listen to the conversation with Shazeen Attari in the inaugural episode of the podcast "A Matter of Degrees," entitled "Give Up Your Climate Guilt" (Stokes \& Wilkinson, 2020); listen also to Blumberg \& Johnson, 2021.) Ifand we stress that these are empirical questions-calling for individuals to go vegan and car-free are the wrong individual changes to focus on, there must be other individual changes to focus on, especially whichever changes best promote needed structural reforms. For example, Whitmarsh et al.'s $(2011,56,59)$ research on how individuals can become not just "carbon-literate" but "carbon-capable" highlights a range of actions that individuals can take beyond changing their consumption habits, such as "voting for a "green" policy; joining an environmental campaign or community action group ... lobbying ... protesting, [and] creating alternative social infrastructures of provision." Clearer communication about the concrete actions individuals can take to bring about structural reform most effectively may be key to combatting climate change. Crucial to this effort will be more fine-grained focus on which particular individual actions are valuable in virtue of their relations to structural change and how most effectively to communicate this information. Table 1 summarizes oppositional and symbiotic thinking about questions like these.

\subsection{Cognitive biases}

The refrain that "structural problems require structural solutions" expresses the thought that effective solutions must be as deep, broad, and durable as their corresponding problem. This idea is familiar and intuitive, but may stem from misleading biases in causal reasoning and social stereotyping. For example, a common source of systematic error in causal reasoning is the belief that causes resemble their effects in size and quality (Nisbett \& Ross, 1980). For example, if told of a person who loses their job-a significant consequence-because their computer crashes, people will infer a "matching" cause, such as a widespread computer virus. If told of another computer crash that yields no significant consequences-no job loss-people will infer a "smaller" cause, such as a malfunctioning cooling fan (LeBoeuf \& Norton, 2012). This "consequence-cause matching" bias may lend unearned credibility to the thought that individual action is causally insignificant in combatting climate change as well.

Metaphors of size that often accompany structuralist proposals can imbue them with connotations of "big," inviting other errors in reasoning. It is sometimes implied that what makes an intervention "structural" is that it is expected to have a large impact. This renders structuralism uninteresting, if not outright empty. That scholars and activists should pursue structural change rather than individual change is hardly controversial if structural change is simply defined as that which has the biggest impact. Moreover, just as ecofeminists have shown that ideas about gender are entwined with ideas about the environment (e.g. Singer, 2020), proposals touted as "largescale," "deep," or "durable" can seem persuasive because they resonate with entrenched masculinist or patriarchal ideology (Roberts \& Utych, 2020). Just like the old advertisement equating meat-eating with maleness ("Real Men Eat Beef"), suggestions that that the "real solutions" to climate change are structural can seem plausible because they implicitly activate widespread but distorting stereotypes. Finally, "big" is vague; it remains unclear what exactly qualifies a policy as big and thereby structural. Such vagueness allows interpretive bias to proliferate; are municipal energy-efficiency regulations structural? How about such regulations in a smaller town (see, e.g. Cozen et al., 2018)? When Walmart switched to LED lightbulbs, was that a structural change? We suspect intuitions about this question might be driven by people's attitudes toward Walmart as much as by their beliefs about what makes a change count as structural. Another key empirical question concerns how climate communication interacts with such cognitive biases. For example, what are the effects on individual-level action of describing the structural reforms needed to meet the climate crisis as "big, deep, and durable," and as requiring changes at the level of national laws, international treaties, and billion-dollar corporations? Such framing may support participation, but it may also undermine it. 


\subsection{Zero sum thinking}

Oppositional thinking presents individuals' time and resources for addressing climate change as zero-sum, as if, for example, recycling comes at the expense of holding extractive industries accountable for pollution. But not all of the choices individuals face are zero-sum. For example, the view that efforts to change consumer behavior distract from more important structural changes presupposes that the former substitute for the latter. Evidence suggests this may be false, and that the relationship is sometimes complementary. For example, individuals who reflect on sustainable individual behavior become more rather than less likely to support structurally-oriented action, such as policy change (Sparkman et al., 2020; see also Geng et al., 2019). A plausible hypothesis explaining this is that people often want to be consistent across the spheres of their personal activity (Bednar et al., 2010). There are many open empirical questions here, and it remains unclear in what contexts "green" consumer behavior complements or substitutes for political behavior in other domains (e.g. does going car-free cause people to take fewer or more pro-climate political actions) (Maki et al., 2019)? But "substitutability" should not be the default assumption, and indeed, lifestyle choices sometimes predict taking political action for the climate (Larson et al., 2015; Steel, 1996; Willis \& Schor, 2012).

Given the scarcity of time and energy, the most important question is not whether to pursue individual or structural change, but which governmental, economic, and social structures we ought to target for change, and what concrete roles individuals can play in efforts to change them. There is, of course, extensive research analyzing comparative packages of structural reform. But these packages need not be portrayed as somehow representing strategies that are alternatives to those aimed at influencing the decisions and behavior of individuals. Rather than presenting these as incompatible genres of change, both can be framed together as essential to serious, multifaceted interventions, components of coordinated strategies that must be pursued in tandem. All interventions to create social change include both individual and structural components, and the individual and structural aspects of every intervention are interdependent, as some have long argued (e.g. Boykoff \& Boykoff 2007; Norton 2007; Whitmarsh et al., 2011; Dannenberg et al., 2012; Jaspal et al., 2014; Mitra 216; Singer, 2020). Consequently, so-called structural reforms always require individual people to support and implement them, while individual choices are always shaped by social structures, which themselves change when individuals direct their agency towards changing them.

\section{Symbiotic thinking}

With some of the potential causes of oppositional thinking in view, we turn to the constructive task of conceiving individual and structural reforms as mutually reinforcing. Numerous lines of research have already made promising inroads. These can be woven together and built upon to develop symbiotic approaches for addressing the most pressing questions for the climate movement.

\subsection{Individual elements of structural change and structural elements of individual change}

One of the most persistent challenges facing the climate movement is mobilizing voters to support pro-climate public policies. Consider carbon taxes, a much-discussed approach to emissionsreduction often portrayed as structural (though not uncontroversial; Mildenberger \& Stokes, 2020). Carbon taxes aim to slow GHG emissions indirectly by manipulating the basic levers and incentives underlying economic activity. In principle, they can work even if almost nobody changes their mind about climate change or makes an intentional decision to reduce their carbon footprint. Rather, traditional economic reasoning predicts that emissions will decline simply because the price of producing them increases.

But passing carbon taxes is politically challenging (Rabe, 2018). Debate over them activates partisanship, identity processes, and economic anxiety. Persuading the public to support taxing carbon 
requires contending with the ways in which individual citizens think about the issues involved. Research in this vein should continue exploring the political psychology relevant to the distributional challenges carbon taxes create (Klenert et al., 2018; Raymond, 2019; Gaikwad et al., Manuscript). Questions such as the following are central: should all citizens receive equal carbon dividends, or should those most impacted by climate change receive the most? Should the money be spent on climate change mitigation? Environmental communication research has demonstrated the greater efficacy of "motivational" or "gain" frames relative to "sacrifice" or "loss" frames (Gifford \& Comeau, 2011; Scannell \& Gifford, 2013). How much, if at all, should messaging be framed in terms of sacrifice, especially if being upfront about costs could mitigate backlash once a policy is implemented (Campbell \& Kay, 2014)? Answering these questions and overcoming the obstacles to passing carbon taxes requires a both/and approach: evaluating an ostensibly structural reform - the tax-and-dividend scheme-in a paradigmatically individualist way by considering how people think and feel about equity and desert, especially in light of their political and social identities.

A similar lesson holds for those advocating for putatively individualist reforms; they can take a both/and approach by thinking of individuals in paradigmatically structuralist ways (Schmitt et al., 2020). The difficulty of persuading individual citizens and political elites to support carbon taxes illustrates this point. Carbon taxes have failed when fossil fuel companies and other opponents have funded massive lobbying and disinformation campaigns about them (Mildenberger, 2020). These campaigns act as structural forces shaping how individuals-both voters and politicians-think about the relevant policies. Lobbying that changes the attitudes of individual citizens thereby changes the incentive structures that shape the behavior of politicians, thus shifting the structural context in which politicians operate. In that newly induced context, resisting carbon taxes can help them win reelection, while endorsing carbon taxes can lead donors to fund a rival candidate, etc. A both/and approach that conceives of individuals as structurally situated would focus attention on ways to change the incentives that shape voters' and politicians' attitudes toward policies like a carbon tax.

The example of changing incentivizes illustrates how thinking of individuals in structuralist terms requires a shift from generic, untargeted efforts to persuade via unadorned appeals to scientific evidence or moral argument-efforts to make "objective" arguments that "should" persuade everybody, but target nobody in particular. Instead, decades of research in environmental communication have explored how attempts to motivate individuals should attend to the specific roles they occupy, and to the constraints and incentives they face in light of their organizational position (e.g. Akin et al., 2020; Cheng et al., 2011; Gifford \& Comeau, 2011; Goodwin \& Dahlstrom, 2014; Hopke, 2017; Jarreau et al., 2017; Jaspal et al., 2014; Kelly, 2019; Krupar \& Krupar, 1989; Lorenzoni et al., 2007; Mitra, 2016; Nisbet, 2009; Scannell \& Gifford, 2013; Shih \& Lin, 2017). For example, efforts to persuade CEOs, elected officials, and other institutional leaders to support pro-climate policies should attend to the particular constraints and incentives faced by each, which, in turn, depend on stakeholders, consumers, constituents, and so on (see $\$ 4.5$; Henderson, 2020).

More generally, changes in social institutions and structures reliably lead to changes in people's minds. Individuals' voting and consumer choices are shaped by social forces that make the available options attractive or distasteful, easy or difficult, efficient or inefficient, etc. Thus, while it is true that enacting a structurally-oriented reform like a carbon tax requires thinking in an individualist way, it is equally true that persuading individuals to support the right reforms requires thinking of their options in a structuralist way. Research on how corporations, laws, media organizations, culture, and communication shape the architectures of choice for individuals is thus crucial to building better symbiotic approaches to decarbonization.

\subsection{Social signaling and social norms}

A second pressing question facing the climate movement has to do with effectively disseminating information in ways that motivate action. While a strong majority of Americans believe in the 
science of climate change, too few understand the consequences of unabated warming (Leiserowitz et al., 2020). Likewise, political representatives tend to be both uninformed about their constituents' beliefs about climate change (Hertel-Fernandez et al., 2019) and skeptical that those beliefs translate into tangible action or influence voting behavior (Willis, 2018). Better information dissemination is needed.

As has long been appreciated in environmental communication (e.g. Antilla, 2005; Hopke, 2017; Jarreau et al., 2017; Nisbet, 2009; Nisbet \& Kotcher, 2009; Scannell \& Gifford, 2013), social norms likely have a key role to play here. Norms are the often-unwritten rules that govern social life (Chudek \& Henrich, 2011; Gelfand, 2018; Kelly \& Setman, 2020; Sripada \& Stich, 2007). They are both "in the head" of individuals and are also elements of social structures. On the one hand, individuals' decisions are shaped by the norms they internalize from their community. On the other, the social norms prevalent in a community are kept in place by collectively shared expectations and common practices. These rules are not explicit policies or formal institutions, but are better conceived as informal institutions or "soft structures" (Davidson \& Kelly, 2020) that provide information about what other people do and what other people think one ought to do (Bicchieri, 2016; Tankard \& Paluck, 2016). Social norms can be leveraged to disseminate climate-related information in durable and motivationally effective ways.

Consider whether to go car-free. One way to evaluate the impact of this choice is to estimate its reduction on one's personal carbon footprint (2.4 tons of CO2-equivalent emissions per person per year (Wynes \& Nicholas, 2017)). But one might also take into account the signals one sends-i.e. the messages one communicates to others-by walking, bicycling, and telling one's friends, family, and co-workers about this choice. This all helps create a different set of social expectations in one's community. Individual choices have material externalities, but they also perform measurable signaling functions, changing perceptions of what is normal and appropriate. Individual actions can communicate genuine values to elite decision-makers as well as other citizens. Governments and businesses may resist change so long as they perceive people to be merely talking about a crisis but going about their business as usual (Hackel \& Sparkman 2018).

Taking this research program further requires addressing a series of empirical questions about the interaction of individuals and social structures. These questions include how much "broadcasting" power different individuals have, which in turn requires exploring individual differences in geographic location (city residents who may not drive versus suburban residents who do). A given person's social location is also key, as prestigious individuals, for example, have disproportionate power to frame and define how others interpret a given issue (Antilla, 2005) and thereby transmit normative information about appropriate responses to it (Henrich \& Gil-White, 2001; Nisbet \& Kotcher, 2009). They can serve, in other words, as "social referents," people from whom others take their cues (Paluck et al., 2016). Visible sacrifices made by these individuals will likely have larger effects on others than "easy" choices (Hackel \& Sparkman, 2018). Indeed, highly visible individuals who publicly advocate for structural change risk being perceived as hypocritical if their own personal choices do not also reflect commitment to pro-climate values (Sparkman \& Attari, 2020).

\subsection{Ease-Impact Tradeoff}

A third pressing question is how researchers should think and communicate about the comparative "bang for the buck" of more structurally-oriented interventions compared to more individuallyoriented interventions. We propose a rule of thumb for this challenge, which we call the "EaseImpact Tradeoff:" all else equal, easier-to-implement reforms are likely to have less impact, whereas harder-to-implement reforms are likely to have more. For example, buying carbon offsets is easy but unlikely to change the course of global events; an enforceable international treaty to curb emissions would be tremendously influential, but is dauntingly complex and likely to be met with opposition. This is a general heuristic, and so not without exceptions. Still, it speaks to the goal of striking 
a good balance of effort invested to expected outcome. The worst interventions will be those that drain attention and resources while making a negligible difference, while the best will be those that are both achievable and impactful.

Taking the Ease-Impact Tradeoff seriously, especially in the context of tailoring messages for various audiences in climate change communication, requires attending to key variables that reflect the intertwined character of individual and structural reform. The following questions can help refine these efforts:

Feasibility: what is possible for individuals who occupy different social positions to do given current political, economic, and cultural constraints (Nielsen et al., 2020; Schmitt et al., 2020)? How demanding is a given intervention of the relevant individuals, given the "choice set" of their social environment? Meanwhile, which public policies and legal frameworks are leaders emboldened to reform, given the opinion and mood of the electorate at a specific point in time, the expected role of interest groups, and so on?

Advisability: what is the potential for an individual pro-climate choice to "catch on" with others rather than decrease the likelihood that they act similarly, particularly in politicized cultures where climate-related behavior signals partisan identity? Similarly in the domain of public policy, what are the chances for long term durability rather than backfire or further politicization? Will the intervention risk unintended consequences? How dangerous might those consequences be?

Knowability: how predictable are the effects of pro-climate individual choices and social-structural policychanges? For example, what key variables determine when consumer choices reach tipping points that render them collectively consequential for reducing system-wide decarbonization (Otto et al., 2020)? Similarly, have proposed decarbonization policies been tried before under similar institutional, political, and cultural circumstances? If so, are the results generalizable?

Answering such questions about any specific intervention demands symbiotic thinking. Framing inquiry in these terms can supplant debate about prioritizing individual or structural change.

\subsection{Initiating roles and sustaining roles}

Fourth, how can the climate community more effectively let people know what they can do, as individuals, to help fight climate change? Oppositional thinking risks creating a motivational morass if individualist-oriented advice-flying less often, eating less meat-is seen as doable but ineffective, while structuralist-oriented advice-creating "structural reform" or "changing the system"-is seen as vague, unachievable, or overwhelming. A symbiotic alternative is to direct individuals to the variety of social roles they can play to create and sustain structural change (Hestres \& Hopke, 2020; Norton, 2007; Scheufele et al., 2004; Whitmarsh et al., 2011; also see Laurence, 2020; Zheng 2018).

A distinction between two broad families of social roles provides another useful heuristic for symbiotic thinking. Individuals can take up initiating roles which may be easily available to them based on their social positions. Scientists, for example, can help initiate change by gathering data relevant to assessing interventions (they can also choose between various initiating roles, such as being a pure scientist, science arbiter, issue advocate, or honest broker (Pielke, 2007)); corporate leaders and employees can initiate change by talking about and seizing opportunities to tie innovation to decarbonization; lawmakers can initiate change by articulating reasons in favor of their preferred policies; columnists and pundits can disseminate and contextualize those plans and the research on which it stands; organizers and activist groups can mobilize support for them; marketers, advertisers, and artists can make them appealing; citizens need to vote for them.

Likewise, a variety of sustaining roles are available to individuals who want to help protect and entrench progress already made. These take up the tasks of ensuring the long-term efficacy of shortterm gains, which in turn can become self-reinforcing as policy changes stimulate changes in beliefs and norms (Kinzig et al., 2013). Sustaining roles involve guiding the social policies and laws through the "fog of enactment" (Stokes, 2020), explaining their benefits to the public in honest and personal ways (e.g. Broockman \& Kalla, 2016; Goodwin \& Dahlstrom, 2014), and building lasting support for them. One challenge here is that some programs (e.g. vaccination) can work "too well," giving the 
impression they are ineffective or unnecessary. Public perception can go awry in other ways, too. President Obama's TARP bailout was instrumental in growing today's wind and solar industry. However, this is not well-known because one unsuccessful piece of this program-the Solyndra grant-received outsized attention (Brady, 2014). Individuals can fill sustaining roles by working to prevent this kind of misperception and backsliding. For example, executives in renewable energy companies benefiting from federal support can speak publicly about the social and economic returns of that government investment, and employees can pressure their executives to do so. Increased support for public investment can in turn shape the costs and incentives surrounding renewable energy, nurturing positive feedback loops of pro-climate action and policy, and building upon a self-reinforcing cycle of change recently dubbed the "green vortex" (Meyer, 2021).

\subsection{Salience}

Finally, how can researchers continue to increase the salience of climate change for voters, and perhaps create a formidable demographic of "single-issue" climate voters who will put pressure on policy makers and others poised to enact structural change? Relatedly, what can researchers do to disrupt the "issue-attention cycle" described by environmental communication researchers (Downs, 1972; McDonald, 2009; Trumbo, 1996) that structures the waxing and waning of public interest in climate change?

Climate researchers can draw inspiration from the symbiotic strategies used by activists focused on other issues. For example, important lessons can be learned from the National Rifle Association (NRA), who have had success even though there is overwhelming bipartisan support in the United States for restrictions on gun ownership. For example, 93\% of Democrats and $82 \%$ of Republicans favor mandatory background checks for private gun sales and gun shows (Schaeffer, 2019). Nevertheless, the NRA has helped block the passing of any federal law that requires such background checks. What the NRA has done, with nearly unrivaled success, is cultivate "a distinct, politicized gun owner social identity over the course of many years, which enables it to influence politics by mobilizing its supporters into frequent and intense political action on its behalf" (Lacombe, 2019, p. 1342). This creates a striking amount of issue salience for these voters. $71 \%$ of Americans who favor less strict gun laws are unwilling to ever vote for political candidates who support gun control; in contrast, among those who favor stricter laws, only $34 \%$ refuse to vote for candidates who do not share their gun preferences (Aronow \& Miller, 2016). For political representatives who occupy positions of structural power, this kind of issue salience translates to reliable votes. The NRA created a constituency by promulgating a gun culture and a social identity for individuals to take up, and then gradually but strategically leveraged the reliable voting habits of those individuals into ties to political elites and leaders of the Republican Party (Han \& Barnett-Loro, 2018). How to create social identities and leverage identity-based thinking to effectively pressure politicianshow to bridge the "value-action gap" on climate change-remains a key strand of research in environmental communication (Akin et al., 2020; Dannenberg et al., 2012; Fox \& Frye, 2010; Hestres \& Hopke, 2020; Jaspal et al., 2014).

This strategy of "outside lobbying" - in which an interest group influences politics by motivating mass organized behavior-exemplifies symbiotic thinking about social change. By creating and then appealing to a specific identity, the organization aims to recruit and motivate individuals to act collectively in virtue of their shared beliefs, values, and positions within a set of social structures. Indeed, recent research suggests that this strategy, pace the kind of zero-sum thinking discussed in $\$ 3.4$, can create positive spillover effects, wherein engaging in one kind of pro-environmental behavior can increase the likelihood that they will also engage in other kinds (Geng et al., 2019). More generally, by leveraging reliable blocks of votes into policy prerogatives, outside lobbyists can achieve structural change by harvesting and directing the power of cumulative individual actions (Skocpol, 2013). 
Transposing this both/and strategy to climate change will not be without challenges (Kurz et al., 2020), though it should be broadly replicable. Indeed, activists and researchers are hard at work in outside lobbying for climate action. Research guided by symbiotic thinking can continue raising the salience of climate change for members of different social groups, as well as helping to build a common identity uniting them. The climate community can also continue advertising the variety of social roles available to individuals within movement activism; the geographies in which individuals are more and less likely to confederate around shared identity (e.g. churches and college campuses); the temporality of identity-mobilization (e.g. before vs. after an extreme weather event); and so on.

\section{Conclusion}

We have argued that what starts as a useful heuristic-individual vs. structural change-is often framed as a zero-sum choice between two opposed ways of making change. We identified four causes of oppositional thinking about individual and structural change and proposed five ways of thinking and acting symbiotically instead. We have described how symbiotic thinking can facilitate social change and climate action, identifying roles for individuals based on their position within social structures and strategies for evaluating the potential impact of their choices.

Future research in environmental communication can build upon these ideas to examine the pragmatic and discursive effects of messages about how individual and structural change relate to each other. We have suggested that the trope of oppositional contrasts between individual and structural reform may undermine climate activism, but this is an empirical question demanding further study. Similarly, we showed how many climate interventions can be framed in either individual or structural terms (\$3.1) and how public discussion of these interventions may be distorted by social stereotypes about, for example, gender (\$3.3). Likewise, while researchers have studied the most effective messages for encouraging individuals to change their consumption habits, a further set of empirical questions regarding the "spillover" effects of these effective messages-for example, on motivating pro-climate political action-are paramount.

Symbiotic thinking keeps firmly in mind that social structures shape the choices and behavior of individual people, while those choices and behavior (re)shape the social structures within which people live. It acknowledges that some individual actions are more influential than others, just as some structurally-oriented policy changes are more advisable than others. But it insists that the way to identify the most promising combinations is by pursuing research and activism that focuses on the relationships between individuals and structures and their joint power to create change.

\section{Acknowledgements}

For their extremely helpful and generous feedback on this project, the authors wish to thank Zeynep Altinay, Corwin Aragon, Donal Carbaugh, Tovar Cerulli, Eugene Chislenko, Steve Depoe, Katherine Gasdaglis, Sandra Gonzalez-Bailon, Guy Grossman, Sally Haslanger, Andrew Iliadis, Robert O. Keohane, Ewan Kingston, Neil Levy, Sunny Lie, Leigh Raymond, Joshua Rottman, Samy Sekar, Gregg Sparkman, and Jason Turcotte. We are also grateful to participants of the Columbia Interdisciplinary Research on Climate Workshop, Group for Empirical Approaches to Morality and Society, Philosophy and the Climate Crisis conference hosted by Philosophers for Sustainability, Workshop on Individual and Structural Change at the CUNY Graduate Center, Yurtfest 2021, Cal Poly Pomona Ethics, Environment, and Society event, and students in Michael Brownstein's spring 2021 seminar, "Climate Change and Social Change."

\section{Disclosure statement}

No potential conflict of interest was reported by the author(s).

\section{Funding}

This work was supported by American Council of Learned Societies. 


\section{References}

Akin, H., Hardy, B. W., \& Jamieson, K. H. (2020). Countering identity-protective Responses to climate change data. Environmental Communication, 14(8), 1111-1126. https://doi.org/10.1080/17524032.2020.1776359

Anderson, E. (2010). The imperative of integration. Princeton University Press.

Antilla, L. (2005). Climate of scepticism: US newspaper coverage of the science of climate change. Global Environmental Change, 15(4), 338-352. https://doi.org/10.1016/j.gloenvcha.2005.08.003

Aronow, P. M., \& Miller, B. T. (2016). Policy misperceptions and support for gun control legislation. The Lancet, 387 (10015), 223. https://doi.org/10.1016/S0140-6736(16)00042-8

Bechtel, M. M., \& Scheve, K. F. (2013). Mass support for global climate agreements depends on institutional design. Proceedings of the National Academy of Sciences, 110(34), 13763-13768. https://doi.org/10.1073/pnas.1306374110

Bednar, J., Bramson, A., Jones-Rooy, A., \& Page, S. (2010). Emergent cultural signatures and persistent diversity: A model of conformity and consistency. Rationality and Society, 22(4), 407-444. https://doi.org/10.1177/ 1043463110374501

Bell, D. (2020). Communitarianism. In E. N. Zalta (Ed.), The Stanford Encyclopedia of philosophy. Spring 2020 Edition. https://plato.stanford.edu/archives/fall2020/entries/communitarianism/

Bicchieri, C. (2016). Norms in the wild: How to diagnose, measure, and change social norms. Cambridge University Press.

Bird, C. (1999). The myth of liberal individualism. Cambridge University Press.

Blumberg, A., \& Johnson, A. E. (2021, March 18). Is your carbon footprint BS? In How to Save a Planet. Gimlet Media. https://gimletmedia.com/shows/howtosaveaplanet/xjh53gn/is-your-carbon-footprint-bs.

Bollinger, B., \& Gillingham, K. (2012). Peer effects in the diffusion of solar photovoltaic panels. Marketing Science, 31 (6), 900-912. https://doi.org/10.1287/mksc.1120.0727

Bolsen, T., \& Druckman, J. (2018). Do partisanship and politicization undermine the impact of a scientific consensus message about climate change? Group Processes \& Intergroup Relations. https://doi.org/10.1177/ 1368430217737855

Boykoff, M. T., \& Boykoff, J. M. (2007). Climate change and journalistic norms: A case-study of US mass-media coverage. Geoforum; Journal of Physical, Human, and Regional Geosciences, 38(6), 1190-1204. https://doi.org/10. 1016/j.geoforum.2007.01.008

Brady, J. (2014). After solyndra loss, U.S. Energy Loan Program Turning A Profit. https://www.npr.org/2014/11/13/ 363572151/after-solyndra-loss-u-s-energy-loan-program-turning-a-profit.

Broockman, D., \& Kalla, J. (2016). Durably reducing transphobia: A field experiment on door-to-door canvassing. Science, 352(6282), 220-224. https://doi.org/10.1126/science.aad9713

Broome, J. (Forthcoming). How much harm does each of us do? In M. Budolfson, D. Plunkett, \& T. McPherson (Eds.), Philosophy and climate change. Oxford University Press.

Brownstein, M. (2018). The Implicit mind: Cognitive architecture, the self, and ethics. Oxford University Press.

Campbell, T. H., \& Kay, A. C. (2014). Solution aversion: On the relation between ideology and motivated disbelief. Journal of Personality and Social Psychology, 107(5), 809-824. https://doi.org/10.1037/a0037963

Cheng, T., Woon, D. K., \& Lynes, J. K. (2011). The Use of Message Framing in the promotion of environmentally Sustainable behaviors. Social Marketing Quarterly, 17(2), 48-62. https://doi.org/10.1080/15245004.2011.570859

Chudek, M., \& Henrich, J. (2011). Culture-gene coevolution, norm-psychology and the emergence of human prosociality. Trends in Cognitive Sciences, 15(5), 218-226. https://doi.org/10.1016/j.tics.2011.03.003

Cox, E., Spence, E., \& Pidgeon, N. (2020). Public perceptions of carbon dioxide removal in the United States and the United Kingdom. Nature Climate Change, 10(8), 744-749. https://doi.org/10.1038/s41558-020-0823-z

Cozen, B., Endres, D., Peterson, T. R., Horton, C., \& Barnett, J. T. (2018). Energy communication: Theory and Praxis Towards a Sustainable Energy future. Environmental Communication, 12(3), 289-294. https://doi.org/10.1080/ 17524032.2017.1398176

Dannenberg, C. J., Hausman, B. L., Lawrence, H. Y., \& Powell, K. M. (2012). The Moral appeal of Environmental discourses: The implication of ethical rhetorics. Environmental Communication, 6(2), 212-232. https://doi.org/ 10.1080/17524032.2012.668856

Davidson, L., \& Kelly, D. (2020). Minding the Gap: Bias, soft structures, and the double life of social norms. Journal of Applied Philosophy, 37(2), 190-210. https://doi.org/10.1111/japp.12351

Downs, A. (1972). Up and down with ecology: The issue-attention cycle. The Public Interest, 28, 38-50.

Dumont, L. (1986). Essays on individualism. University of Chicago Press.

Elliot, B. (2016). Natural catastrophe: Climate change and Neoliberal governance. Edinburgh University Press.

Elliott, C. (2004). Better than well: American medicine meets the American dream. Norton.

Elster, J. (1989). Nuts and bolts for the social sciences. Cambridge University Press.

Feinberg, M., \& Willer, R. (2013). The Moral roots of Environmental attitudes. Psychological Science, 24(1), 56-62. https://doi.org/10.1177/0956797612449177

Fox, R. L., \& Frye, J. J. (2010). Tensions of praxis: A New taxonomy for social movements. Environmental Communication, 4(4), 422-440. https://doi.org/10.1080/17524032.2010.520021 
Frank, R. (2020). Under the influence: Putting Peer pressure to work. Princeton University Press.

Franzen, A., \& Vogl, D. (2013). Two decades of measuring environmental attitudes: A comparative analysis of 33 countries. Global Environmental Change, 23(5), 1001-1008. https://doi.org/10.1016/j.gloenvcha.2013.03.009

Gaikwad, N., Genovese, F., \& Tingley, D. Manuscript. Vulnerability, compensation, and support for climate policies.

García-Sánchez, E., Van der Toorn, J., Rodríguez-Bailón, R., \& Willis, G. B. (2019). The vicious cycle of economic inequality: The role of ideology in shaping the relationship between "what is" and "what ought to be" in 41 countries. Social Psychological and Personality Science, 10(8), 991-1001. https://doi.org/10.1177/ 1948550618811500

Gardiner, S. M. (2011). A perfect moral storm: The ethical tragedy of climate change. Oxford University Press.

Gelfand, M. (2018). Rule makers, rule breakers: How tight and loose cultures wire Our world. Scribner.

Geng, L., Chen, Y., Ye, L., Zhou, K., \& Chen, Y. (2019). How to predict future pro-environmental intention? The spillover effect of electricity-saving behavior under environmental and monetary framing. Journal of Cleaner Production, 233, 1029-1037. https://doi.org/10.1016/j.jclepro.2019.06.088

Giddens, A. (1986). The constitution of society. University of California Press.

Gifford, R., \& Comeau, L. (2011). Message framing influences perceived climate change competence, engagement, and behavioral intentions. Global Environmental Change, 21(4), 1301-1307. https://doi.org/10.1016/j.gloenvcha. 2011.06.004

Goodwin, J., \& Dahlstrom, M. (2014). Communication strategies for earning trust in climate change debates. Wiley Interdisciplinary Reviews: Climate Change, 5(1), 151-160, https://doi.org/10.1002/wcc.262

Grandin, G. (2019). The end of the myth: From the frontier to the border wall in the mind of America. Metropolitan Books.

Greenberg, P. (2021). The Climate Diet: 50 simple ways to Trim Your Carb footprint. Penguin Books.

Griffin, P. (2017). The Carbon majors database. https://b8f65cb373b1b7b15feb-c70d8ead6ced550b4d987d7c03f cdd1d.ssl.cf3.rackcdn.com/cms/reports/documents/000/002/327/original/Carbon-Majors-Report-2017.pdf.

Gustafson, A., Rosenthal, S.A., Ballew, M.T., Goldberg, M.H., Bergquist, P., Kotcher, J.E., Maibach, E.W. and Leiserowitz, A. (2019). The development of partisan polarization over the Green New deal. Nature Climate Change, 9(12), 940-944. https://doi.org/10.1038/s41558-019-0621-7

Hackel, L., \& Sparkman, G. (2018). Reducing your carbon footprint still matters. Slate. https://slate.com/technology/ 2018/10/carbon-footprint-climate-change-personal-action-collective-action.html.

Hagmann, D., Ho, E. H., \& Loewenstein, G. (2019). Nudging out support for a carbon tax. Nature Climate Change, 9 (6), 484-489. https://doi.org/10.1038/s41558-019-0474-0

Han, H., \& Barnett-Loro, C. (2018). To support a stronger climate movement, focus research on building collective power. Frontiers in Communication. https://doi.org/10.3389/fcomm.2018.00055

Harrison, K., \& Sundstrom, L. M. (2007). The comparative Politics of climate change. Global Environmental Politics, 7(4), 1-18. https://doi.org/10.1162/glep.2007.7.4.1

Haslanger, S. (2015). Distinguished lecture: Social structure, narrative and explanation. Canadian Journal of Philosophy, 45(1), 1-15. https://doi.org/10.1080/00455091.2015.1019176

Heglar, M. A. I work in the environmental movement. I don't care if you recycle. Vox, https://www.vox.com/thehighlight/2019/5/28/18629833/climate-change-2019-green-new-deal.

Henderson, R. (2020). Climate in the boardroom: Struggling to reconcile business as usual \& the End of the World as We know It. Daedalus, 149(4), 118-124. https://doi.org/10.1162/daed_a_01821

Henrich, J. (2020). The WEIRDest people in the world: How the West became psychologically peculiar and particularly prosperous. Farrar, Straus and Giroux.

Henrich, J., \& Gil-White, F. (2001). The evolution of prestige: Freely conferred deference as a mechanism for enhancing the benefits of cultural transmission. Evolution and Human Behavior, 22(3), 165-196. https://doi.org/10. 1016/S1090-5138(00)00071-4

Hertel-Fernandez, A., Mildenberger, M., \& Stokes, L. C. (2019). Legislative staff and representation in congress. American Political Science Review, 113(1), 1-18. https://doi.org/10.1017/S0003055418000606

Hestres, L. E., \& Hopke, J. E. (2020). Fossil fuel divestment: Theories of change, goals, and strategies of a growing climate movement. Environmental Politics, 29(3), 371-389. https://doi.org/10.1080/09644016.2019.1632672

Hopke, J. (2017). To have impact, the people's climate March needs to reach beyond activists. The Conversation. $\mathrm{http}$ //theconversation.com/to-have-impact-the-peoples-climate-march-needs-to-reach-beyond-activists-75974

Hourdequin, M. (2010). Climate, collective action and individual ethical obligations. Environmental Values, 19(4), 443-464. https://doi.org/10.3197/096327110X531552

Jamieson, D. (2007). The moral and political challenges of climate change. Creating a Climate for Change: Communicating Climate Change and Facilitating Social Change, 475-482. https://doi.org/10.1017/CBO9780511535871.033

Jarreau, P. B., Altinay, Z., \& Reynolds, A. (2017). Best practices in Environmental communication: A case study of louisiana's coastal crisis. Environmental Communication, 11(2), 143-165. https://doi.org/10.1080/17524032.2015.1094103

Jaspal, R., Nerlich, B., \& Cinnirella, M. (2014). Human Responses to climate change: Social representation, identity and socio-psychological action. Environmental Communication, 8(1), 110-130. https://doi.org/10.1080/17524032. 2013.846270 
Kelly, D., \& Setman, S. (2020). The Psychology of normative cognition. Stanford Encyclopedia of Philosophy. https:// plato.stanford.edu/archives/spr2021/entries/psychology-normative-cognition/

Kelly, M. R. (2019). Communities, collaboration, and climate change adaptation: Case studies from coastal maine and oregon. Applied Environmental Education \& Communication, 18(1), 68-78. https://doi.org/10.1080/1533015X. 2018.1434024

Kinzig, A.P., Ehrlich, P.R., Alston, L.J., Arrow, K., Barrett, S., Buchman, T.G., Daily, G.C., Levin, B., Levin, S., Oppenheimer, M. and Ostrom, E. (2013). Social norms and global environmental challenges: The complex interaction of behaviors, values, and policy. BioScience, 63(3), 164-175. https://doi.org/10.1525/bio.2013.63.3.5

Klenert, D., Mattauch, L., Combet, E., Edenhofer, O., Hepburn, C., Rafaty, R. and Stern, N. (2018). Making carbon pricing work for citizens. Nature Climate Change, 8(8), 669-677. https://doi.org/10.1038/s41558-018-0201-2

Krupar, K. R., \& Krupar, J. J. (1989). Communication strategies for resolving environmental issues. International Journal of Environmental Studies, 34(1-2), 11-23. https://doi.org/10.1080/00207238908710510

Kurz, T., Prosser, A. M., Rabinovich, A., \& O’Neill, S. (2020). Could vegans and lycra cyclists be Bad for the planet? Theorizing the role of moralized minority practice identities in Processes of societal-level change. Journal of Social Issues, 76(1), 86-100. https://doi.org/10.1111/josi.12366

Lacombe, M. J. (2019). The political weaponization of gun owners: The national Rifle association's cultivation, dissemination, and use of a group social identity. The Journal of Politics, 81(4), 1342-1356. https://doi.org/10.1086/ 704329

Larson, L. R., Stedman, R. C., Cooper, C. B., \& Decker, D. J. (2015). Understanding the multi-dimensional structure of pro-environmental behavior. Journal of Environmental Psychology, 43, 112-124. https://doi.org/10.1016/j.jenvp. 2015.06.004

Laurence, B. (2020). The question of the agent of change. Journal of Political Philosophy, 28(4), 355-377. https://doi. org/10.1111/jopp.12204

LeBoeuf, R., \& Norton, M. (2012). Consequence-Cause matching: Looking to the consequences of events to infer their causes. Journal of Consumer Research, 39(1), 128-141. https://doi.org/10.1086/662372

Leiserowitz, A., Maibach, E., Rosenthal, S., Kotcher, J., Bergquist, P., Ballew, M.T., Goldberg, M. and Gustafson, A. (2020). Climate change $n$ the American mind: April 2020. Yale University and George Mason University.

Lorenzoni, I., Nicholson-Coleb, S., \& Whitmarsh, L. (2007). Barriers perceived to engaging with climate change among the UK public and their policy implications. Global Environmental Change, 17(3-4), 445-459. https:// doi.org/10.1016/j.gloenvcha.2007.01.004

Madva, A. (2016). A plea for anti-anti-individualism: How oversimple Psychology misleads social policy. Ergo, an Open Access Journal of Philosophy, 3(27), 701-728. https://doi.org/10.3998/ergo.12405314.0003.027.

Madva, A. (2017). Biased against debiasing: On the role of (institutionally sponsored) self-transformation in the struggle against prejudice. Ergo, an Open Access Journal of Philosophy, 4(6), 145-179. http://doi.org/10.3998/ ergo.12405314.0004.006.

Madva, A. (2020). Individual and structural interventions. In E. Beeghly, \& A. Madva (Eds.), An Introduction to Implicit bias: Knowledge, justice, and the social mind, 1st ed. (pp. 233-270). Routledge. https://doi.org/10.4324/ 9781315107615-12

Maki, A., Carrico, A. R., Raimi, K. T., Truelove, H. B., Araujo, B., \& Yeung, K. L. (2019). Meta-analysis of proenvironmental behaviour spillover. Nature Sustainability, 2(4), 307-315. https://doi.org/10.1038/s41893-0190263-9

Mann, M., \& Brockopp, J. (2019). You can't save the climate by going vegan. corporate polluters must be held accountable. USA Today. https://www.commondreams.org/views/2019/06/03/you-cant-save-climate-going-vegancorporate-polluters-must-be-held-accountable.

Markus, H., \& Kitayama, S. (2010). Cultures and selves: A cycle of mutual constitution. Perspectives on Psychological Science, 5(4), 420-430. https://doi.org/10.1177/1745691610375557

Mauldin, L. (2021, March 26). Idk who came up with this, but I am SO here for this deeply sociological meme https:// t.co/rdu44hEyvK [Tweet]. @mauldin_laura. https://twitter.com/mauldin_laura/status/1375443312480563204.

McDonald, S. (2009). Changing climate, changing minds: Applying the literature on media effects, public opinion, and the issue-attention cycle to increase public Understanding of climate change. International Journal of Sustainability Communication, 4, 45-63.

Merritt, A., Effron, D., \& Monin, B. (2010). Moral-Self-Licensing: When being Good frees Us to Be Bad,". Social and Personality Psychology Compass, 4/5(5), 344-357. https://doi.org/10.1111/j.1751-9004.2010.00263.x

Meyer, R. (2021). "How the U.S. Made Progress on Climate Change Without Ever Passing," The Atlantic, June 16, 2021. https://www.theatlantic.com/science/archive/2021/06/climate-change-green-vortex-america/619228/.

Mildenberger, M. (2020). Carbon captured: How business and labor control climate politics. MIT Press.

Mildenberger, M., \& Stokes, L. (2020). The trouble with carbon pricing. Boston Review. http://bostonreview.net/ science-nature-politics/matto-mildenberger-leah-c-stokes-trouble-carbon-pricing.

Mitra, R. (2016). Reconstituting "america": The Clean Energy economy ventriloquized. Environmental Communication, 10(2), 269-288. https://doi.org/10.1080/17524032.2015.1047885 
Nielsen, K. S., Stern, P., Dietz, T., Gilligan, J., Vuuren, D. P., Figueroa, M. J., Folke, C., Gwozdz, W., Ivanova, D., Reisch, L., Vandenbergh, M. P., Wolske, K. S., \& Wood, R. (2020). Improving climate change mitigation analysis: A framework for Examining feasibility. One Earth, 3(3), 325-336. https://doi.org/10.1016/j.oneear.2020.08.007

Nisbet, M. C. (2009). Communicating climate change: Why frames Matter for public engagement. Environment: Science and Policy for Sustainable Development, 51(2), 12-23. https://doi.org/10.3200/ENVT.51.2.12-23

Nisbet, M. C., \& Kotcher, J. E. (2009). A Two-step flow of influence?: Opinion-leader campaigns on climate change. Science Communication, 30(3), 328-354. https://doi.org/10.1177/1075547008328797

Nisbett, R., \& Ross, L. (1980). Human inference: Strategies and shortcomings of social judgment. Prentice-Hall.

Nisbett, R. E. (2004). The geography of thought: How asians and westerners think differently ... and Why. Free Press.

North, D. (1991). Institutions. Journal of Economic Perspectives, 5(1), 97-112. https://doi.org/10.1257/jep.5.1.97

Norton, T. (2007). The structuration of public participation: Organizing Environmental control. Environmental Communication, 1(2), 146-170. https://doi.org/10.1080/17524030701642546

Olausson, U. (2010). Towards a European identity? The news media and the case of climate change. European Journal of Communication, 25(2), 138-152. https://doi.org/10.1177/0267323110363652

Oreskes, N., \& Conway, E. (2010). Merchants of doubt: How a handful of Scientists obscured the truth on issues from tobacco smoke to global warming. Bloomsbury Press.

Otto, I.M., Donges, J.F., Cremades, R., Bhowmik, A., Hewitt, R.J., Lucht, W., Rockström, J., Allerberger, F., McCaffrey, M., Doe, S.S. and Lenferna, A. (2020). Social tipping dynamics for stabilizing earth's climate by 2050. Proceedings of the National Academy of Sciences, 117(5), 2354-2365. https://doi.org/10.1073/pnas.1900577117

Paluck, E. L., Shepherd, H., \& Aronow, P. M. (2016). Changing climates of conflict: A social network experiment in 56 schools. PNAS Proceedings of the National Academy of Sciences of the United States of America, 113(3), 566-571. https://doi.org/10.1073/pnas.1514483113

Parr, A. (2012). The wrath of capital: Neoliberalism and climate change politics. Columbia University Press.

Pielke, R. A. (2007). The honest broker: Making sense of Science in policy and politics. Cambridge University Press.

Post, S., Kleinen-von Königslöw, K., \& Schäfer, M. S. (2019). Between Guilt and obligation: Debating the responsibility for climate change and Climate Politics in the media. Environmental Communication, 13(6), $723-739$. https://doi.org/10.1080/17524032.2018.1446037

Rabe, B. (2018). Can We price carbon? MIT Press.

Rand, A. (1964). The virtue of selfishness: A New concept of egoism. Signet Press.

Raymond, L. (2016). Reclaiming the atmospheric commons. The MIT Press.

Raymond, L. (2019). Policy perspective: Building political support for carbon pricing-lessons from cap-and-trade policies. Energy Policy, 134, 110986. https://doi.org/10.1016/j.enpol.2019.110986

Raymond, L., Weldon, S., Kelly, D., Arriaga, X., \& Clark, A. (2014). Making change: Norms and informal institutions as solutions to "intractable" global problems. Political Research Quarterly, 67(1), 197-211. https://doi.org/10.1177/ 1065912913510786

Roberts, D. C., \& Utych, S. M. (2020). Linking gender, language, and partisanship: Developing a Database of masculine and feminine words. Political Research Quarterly, 73(1), 40-50. https://doi.org/10.1177/1065912919874883

Scannell, L., \& Gifford, R. (2013). Personally relevant climate change: The role of place attachment and local versus global message framing in engagement. Environment and Behavior, 45(1), 60-85. https://doi.org/10.1177/0013916511421196

Schaeffer, K. (2019). Share of americans who favor stricter gun laws has increased since 2017. Pew Research Center. https://www.pewresearch.org/fact-tank/2019/10/16/share-of-americans-who-favor-stricter-gun-laws-hasincreased-since-2017/.

Scheufele, D. A., Nisbet, M. C., Brossard, D., \& Nisbet, E. C. (2004). Social structure and citizenship: Examining the impacts of social setting, network heterogeneity, and informational variables on political participation. Political Communication, 21(3), 315-338. https://doi.org/10.1080/10584600490481389

Schmitt, M. T., Neufeld, S. D., Mackay, C. M., \& Dys-Steenbergen, O. (2020). The perils of explaining climate inaction in terms of psychological barriers. Journal of Social Issues, 76(1), 123-135. https://doi.org/10.1111/josi.12360

Sewell, W. (2005). Logics of history. University of Chicago Press.

Shih, T.-J., \& Lin, C.-Y. (2017). Developing Communication strategies for mitigating actions against Global Warming: Linking framing and a dual processing model. Environmental Communication, 11(6), 840-858. https://doi.org/10.1080/17524032.2016.1154886

Singer, N. R. (2020). Toward intersectional ecofeminist Communication studies. Communication Theory, 30(3), 268289. https://doi.org/10.1093/ct/qtz023

Sinnott-Armstrong, W. (2005). It's not my fault: Global warming and individual moral obligations. Perspectives on Climate Change: Science, Economics, Politics, Ethics-Advances in the Economics of Environmental Research, 5, 293315. https://sites.duke.edu/wsa/papers/files/2011/05/wsa-itsnotmyfault2005.pdf

Skocpol, T. (2013). Naming the Problem: What it will take to counter extremism and engage Americans in the fight against global warming. Symposium presentation, The Politics of America's Fight Against Global Warming.

Soutter, A. R. B., Bates, T., \& Mõttus, R. (2020). Big five and HEXACO Personality traits, proenvironmental attitudes, and behaviors: A meta-analysis. Perspectives on Psychological Science, 15(4), 913-941. https://doi.org/10.1177/ 1745691620903019 
Sparkman, G., \& Attari, S. Z. (2020). Credibility, communication, and climate change: How lifestyle inconsistency and do-gooder derogation impact decarbonization advocacy. Energy Research \& Social Science, 59, 101290. https://doi.org/10.1016/j.erss.2019.101290

Sparkman, G., Attari, S. Z., \& Weber, E. U. (2020). Focusing on personal sustainable behavior rarely hinders and can boost climate policy support. Manuscript submitted for publication.

Sripada, C., \& Stich, S. (2007). A framework for the psychology of norms. In P. Carruthers, S. Laurence, \& S. Stich (Eds.), The innate mind: Culture and cognition (pp. 280-301). Oxford University Press.

Steel, B. S. (1996). Thinking globally and acting locally? Environmental attitudes, behaviour and activism. Journal of Environmental Management, 1(1), 27-36. https://doi.org/10.1006/jema.1996.0033

Stokes, L. (2020). Short circuiting policy: Interest groups and the battle over Clean Energy and Climate Policy in the American states. Oxford University Press.

Stokes, L. C., \& Wilkinson, K. (2020, October 15). Give up your climate guilt (No. 1). In A Matter of Degrees Podcast. https://www.degreespod.com/episodes/episode-01.

Stuart, D., Gunderson, R., \& Peterson, B. (2020). Climate change solutions: Beyond the capital-climate contradiction. University of Michigan Press.

Sunday, C. (2017, October 18). 9 Things you can do to save the environment. Nature's Path [Blog]. https://www. naturespath.com/en-us/blog/nine-things-you-can-do-to-save-the-environment/.

Tankard, M. E., \& Paluck, E. L. (2016). Norm perception as a vehicle for social change. Social Issues and Policy Review, 10(1), 181-211. https://doi.org/10.1111/sipr.12022

Taylor, C. (1989). Sources of the self: The making of modern identity. Harvard University Press.

Thaler, A. (2021, March 25). Https://t.co/xNjObLTkoO [Tweet]. @drandrewthaler. https://twitter.com/ drandrewthaler/status/1375084220910034953.

Tollefson, J. (2021). COVID curbed carbon emissions in 2020-But not by much. Nature, 589(7842), 343-343. https://doi.org/10.1038/d41586-021-00090-3

Trumbo, C. (1996). Constructing climate change: Claims and frames in US news coverage of an environmental issue. Public Understanding of Science, 5(3), 269-283. https://doi.org/10.1088/0963-6625/5/3/006

Trumbo, C. W., \& Shanahan, J. (2000). Social research on climate change: Where we have been, where we are, and where we might go. Public Understanding of Science, 9(3), 199-204. https://doi.org/10.1088/0963-6625/9/3/002

Vinyeta, K., Whyte, K. P., \& Lynn, K. (2015). Climate change through an intersectional lens: Gendered vulnerability and resilience in indigenous communities in the United States. Gen. Tech. Rep. PNW-GTR-923. U.S. Department of Agriculture, Forest Service, Pacific Northwest Research Station.

Webb, J. (2012). Climate change and society: The chimera of behaviour change technologies. Sociology, 46(1), 109125. https://doi.org/10.1177/0038038511419196

Wetts, R. (2019). Models and morals: Elite-oriented and value-neutral discourse dominates American organizations' framings of climate change. Social Forces, https://doi.org/10.1093/sf/soz027.

Wetts, R. (2020). In climate news, statements from large businesses and opponents of climate action receive heightened visibility. Proceedings of the National Academy of Sciences, 117(32), 19054-19060. https://doi.org/10.1073/ pnas. 1921526117

Whitmarsh, L., Seyfang, G., \& O’Neill, S. (2011). Public engagement with carbon and climate change: To what extent is the public 'carbon capable'? Global Environmental Change, 21(1), 56-65. https://doi.org/10.1016/j.gloenvcha. 2010.07.011

Willis, M. M., \& Schor, J. B. (2012). Does changing a light bulb lead to changing the world? Political action and the conscious consumer. The ANNALS of the American Academy of Political and Social Science, 644(1), 160-190. https://doi.org/10.1177/0002716212454831

Willis, R. (2018). How members of parliament understand and respond to climate change. The Sociological Review, 66 (3), 475-491. https://doi.org/10.1177/0038026117731658

Wynes, S., \& Nicholas, K. (2017). The climate mitigation gap: Education and government recommendations miss the most effective individual actions. Environmental Research Letters, 12(7), 074024. https://doi.org/10.1088/17489326/aa7541

Yee, V., \& Glanz, J. (2021, July 17). How one of the world's biggest ships jammed the Suez Canal. The New York Times. https://www.nytimes.com/2021/07/17/world/middleeast/suez-canal-stuck-ship-ever-given.html.

Zheng, R. (2018). What is my role in changing the system? A new model of responsibility for structural injustice. Ethical Theory and Moral Practice, 21(4), 869-885. doi:10.1007/s10677-018-9892-8 